\title{
The Use of L1 in English Reading Lessons of Hong Kong Chinese-Medium Secondary Schools
}

\section{Ching Yau Wong}

MSc, University of Edinburgh, United Kingdom, cywong.edith@gmail.com

This study examined the use of first language in English reading lessons and the perceptions of teachers and students towards it in three Hong Kong Chinesemedium secondary schools. The data comprised three teachers and sixty-three Form 2 students' participation and responses in (i) 3 classroom observations about how L1 was used in actual teaching and learning settings, (ii) survey forms gathering the frequency of participants using L1 teaching and learning strategies (based on the three teachers and nineteen selected students from the pool), and (iii) subsequent in-depth interviews concerning their perceptions about using L1 in English reading lessons. The findings revealed that (i) the use of L1 bottom-up language focused teaching strategies and condition-oriented teaching and learning strategies were effective for teaching and learning in English reading lessons and (ii) there was a negative relationship between students' proficiency in English and the use of L1. The study concluded that the use of first language in English reading lessons brought positive effects on the second language learning in English reading, especially when students' English proficiency and teaching contexts were taken into consideration.

Keywords: second language acquisition, content and language integrated learning, classroom interaction, learner motivation, code-switching, bilingual education

\section{INTRODUCTION}

Over the past few decades, there was a rise in discussion about the use of first language (L1) in English classrooms, and it has become a controversial issue both locally in Hong Kong and internationally elsewhere. The majority of the general public tends to advocate using English (i.e. the second language) entirely in English lessons (Leung, 2010). They believe that the use of L1 has an interfering and detrimental effect on learners, which may limit their use of L2 in the classrooms and thus diminish their process of L2 acquisition. However, an increase amount of local research reveals that moderate and judicious use of L1 could aid teaching and learning in L2 especially to lower ability learners (Lo, 2015; Tang, 2002). Although this controversy has existed for at least two decades, little research has touched on this "sensitive matter" (Shum, 2008,

Citation: Wong, C. Y. (2020). The Use of L1 in English Reading Lessons of Hong Kong ChineseMedium Secondary Schools. International Journal of Instruction, 13(2), 863-880. https://doi.org/10.29333/iji.2020.13258a 
p.4). Most of the overseas and local research (e.g. Castilla, 2015; Savaşç1, 2013; Wandika, 2014) merely focused on the general effects that L1 has on English lessons as a whole, without looking at the impacts of L1 for teachers and students to teach and acquire each language skill respectively.

According to the Curriculum Development Council (2002), the ability to read and comprehend is crucial for learners to achieve academic and intellectual purposes. Their acquisition of new knowledge from reading benefits them in both formal education and lifelong learning. In fact, some teachers and students with low English proficiency were found to use a certain degree of Cantonese in the reading lessons for teaching and learning, yet it is a taboo for schools in Hong Kong to acknowledge and discuss about this issue due to the pressure given by the public that L2 should be the only language which appears in English lessons (Li, 2017). Since the research focuses on the use of L1 in the English reading lessons is limited, it is essential to further investigate whether the use of L1 could contribute in the lessons in terms of teaching and learning.

\section{LITERATURE REVIEW}

\section{Controversy of an English-Only Classroom}

Throughout the history of language teaching, we have moved from the 'Grammar Translation Method', in which L2 is learnt through L1, to another extreme, that is no L1 at all. It seemed evident that if the goal in Second Language Acquisition (SLA) was communicative competence in L2, learners should have as much exposure of the target language as possible in a classroom, so to replicate the natural learning process through mastering a mother tongue (Lewis, 1993). Yet over the years, research mentioned that there were learners who showed hesitation and reluctance to speak and write in L2 while having English lessons, such claim cast doubt on whether English-only classrooms benefited all learners in learning English as a second language (Castilla, 2015; Wandika, 2014). Regarding this question, various studies were conducted to investigate the causes of learners' struggles under English-only environment, in which learner's ability and motivation were identified as the two major causes.

There is an undeniable link between learners' achievement in L2 and their participation in the classrooms. According to Liu (2005) and Hamouda (2012), learners who participate actively tended to have better achievement in L2 and vice versa. Their claim was supported by earlier studies indicating that low English proficiency was one of the main reasons that led to learners' reticence in ESL classes (Jackson, 2002). The lack of vocabulary and comprehensible input indeed hindered learners to communicate in English-only classrooms, where learners did not receive or had enough words and ideas to communicate with their peers and teachers during class time. With the sense of inability, they were encouraged to be silent listeners rather than active participants in the classroom which contradicted to the initial goal of SLA (Cortazzi \& Jin, 1996). Studies also claimed that most L2 learners found it important to express their ideas fully during classroom discussions, as they wanted to provide an answer with appropriate use of the language; however, seldom did they know exactly what and how to express with L2 (Castilla, 2015). It was therefore more discouraging when learners made mistakes and 
received negative evaluation from teachers and classmates in ESL classrooms. McCroskey (1992) also mentioned that unfamiliarity with academic discourse and lacking knowledge in the subject matter could turn into communication apprehension, which contributed to the low motivation level among L2 learners in classroom interaction. These struggles maximized learners' unwillingness in using English as a vehicle for spoken communication in the class as they generated fear, anxiety and decrease confidence.

Learner' ability and motivation seemed to be negatively related with the amount of L2 use in the classrooms based on the insights from the above studies. During the early 1990 s, some initial work was done to quantify the amount of L1 and L2 use in non English-only ESL classrooms. Among these studies, a few of them explored the purposes and types of discourse of which L1 and L2 were being employed by teachers and students during class time (Auerbach, 1993; Bialystok, 2001). An increased amount of evidence had proven that L1 occupied a central place in SLA. These researchers supported the idea that L1 was a permanent language resource that motivated learners and enabled them to communicate and construct knowledge in learning L2. It played a crucial role in facilitating and mediating L2 learning as formal instruction. Such important role was particularly evident in L2 literacy development especially in L2 comprehension.

\section{Development of L1 Teaching and Learning Strategies in English Reading Classrooms}

Effective reading was essential for success in acquiring a second language, as it was "the basis of instruction in all aspects of language learning" (Mikulecky, 2008, p.1). It was found that L2 learners tended to seek constantly to facilitate their reading tasks by making use of their prior knowledge which consisted of what they had already known about the target language and of their knowledge of L1 (Faerch \& Kasper, 1980). Moreover, L2 "input" did not necessary link with "intake" as the exclusive L2 use might expose students to a language that they were unable to process and assimilate into their linguistic framework. That was why teachers could use L1 as a useful resource for learners to sift the L2 while they received L2 input consciously and subconsciously. Yet many teachers still insisted to create an English-only classroom without understanding the needs of the students, and students eventually failed to get meaning across and led to incomprehension (Harbord, 1992). Therefore, researchers postulated that it was valid to consider whether L2 "input" might become "intake" more readily if teachers used L1 judiciously to catalyse the intake process in some ways.

Concerning the interrogation, various researchers underwent several inspections and discovered that teachers occasionally used L1 to help students in English learning. Atkinson (1993) gathered the findings from the researchers and proposed that using L1 enhanced meaning-making of reading, which was one of the important aspects in reading. He suggested that L1 could facilitate students to connect words with corresponding meaning in different stages of a lesson. Teachers were found to use L1 to explain ambiguous and difficult words, ideas and concepts to aid comprehension throughout the lessons by using prompts and instructions (Cook, 2001). Moreover, apart 
from using L1 to facilitate construction and negotiation of meanings for reading, teachers tended to create an interactive effect through expressing solidarity and empathy in L1 to build rapport with students and encourage them to use L2. Teachers' humour, personal talks and comments in L1 was found to bring comfort to students in reducing their anxiety towards the target language (Crawford, 2004).

Besides, L1 was also found to foster peer learning throughout the lessons. Studies showed that the use of L1 in group discussions was the precursor to help students generate more ideas for answering questions about the lesson content (Carson \& Kashihara, 2012). It was reported that students maintained each other's interest and attention with a higher level of motivation to develop strategies to complete a task with L1 (Anton \& DiCamilla, 1998). As students were being more comfortable and confident, their sense of control towards the tasks increased and therefore were able to produce and express more mature thoughts and ideas (Meyer, 2008). Polio and Duff's study (1994) reported that students tended to use L1 for asking a classmate to explain a new point in the lesson, explaining a new point in the lesson to their classmates and chatting with classmates about topics that were connected to the lesson.

The above showed that using L1 teaching and learning strategies in English reading lessons could help students as they elevated content knowledge and motivation. Despite such recognition of the values of L1 by overseas studies, there were still concerns about its practice locally. In some studies (as stated by Hamouda, 2012), researchers particularly singled out Asian learners and mentioned that they showed higher degree of passiveness and reticence during class time when compared to other overseas learners. This claim reflected that there was a need to further examine the use of L1 in Hong Kong English reading lessons.

\section{Theoretical Framework of the Study}

Although there is limited research on the L1 use by teachers and students in Hong Kong Chinese Medium-of-Instruction (CMI) secondary schools' English reading lessons, the reasons for using L1 teaching and learning strategies could still be categorized into different aspects based on the conclusions drawn by researchers mentioned earlier. The aforementioned L1 teaching and learning strategies could be divided into three "distinct yet overlapping" groups according to the model proposed by von Dietze and von Dietze (2007). They are Top-Down Language Focused, Bottom-Up Language Focused and Conditional-Oriented groups. These focuses can be traced back to the interactive models of reading which was first proposed by Rumelhart in 1977.

The top-down language focused group stressed on using L1 to help students access prior knowledge of the topic before they attempt a cognitively challenging L2 activity. Teachers' sharing on personal experience, or stories and examples related to a particular culture or social issue were found to provide a platform for lower ability students to activate their schema more easily, and it ensured that they were ready to receive input and contribute in the lessons (Hidayati, 2012). Meanwhile, the bottom-up language focused group emphasized the ways that L1 was used to facilitate students' decoding stage of words and phrases, it was the fundamental stage to acquire the content 
knowledge and the L2 language in the reading lessons (Lo, 2015). According to a vast majority of research in the field (e.g. Antón \& DiCamilla, 1998; Lantolf, 2001; Meyer, 2008), translation, explanation and elaboration of vocabulary and concepts in L1 for low ability students were identified to be helpful as this group of students could be given similar or even extra information of the L2 target items and thus gaining a sense of control over the comprehensible input.

Apart from the top-down and bottom-up focuses, the condition-oriented group's elements also played a crucial part in L2 classrooms. It accentuated the use L1 to create ideal conditions for L2 learning to take place, in which the interactions between teachers and students, as well as students and students played a significant role in enhancing and maintaining the motivation level of lower ability learners. Teachers had the obligation to ensure students were confident and comfortable in the lesson. It could be done by maintaining contact with them in L1 through making clarification towards students' queries on the lesson content and giving group or individual feedback of their performance. Moreover, effective L2 learning could also happen when students express themselves in L1 when they find difficulties finding a L2 equivalence during lesson time or group discussions (Cook, 2001). Such use of L1 could maintain their interests in the task and it also fostered peer learning in the classroom.

\section{Purpose of the Study}

The aforementioned L1 teaching and learning strategies were reported to have significant positive impacts on lower ability students in English reading lessons, yet the implementation is still controversial in Hong Kong with limited research. To fill the gap, this research attempted to put the focus on the actual use of L1 in Hong Kong Chinesemedium secondary schools' English reading lessons and the perceptions of teachers and students' use of L1 in the reading lessons. With the help of the theoretical model, the pedagogical and affective impacts of using L1 on English reading lessons were explored in this study and the research questions are:

(1) How does the use of L1 help teaching and learning in English reading lessons of Chinese-medium secondary schools in Hong Kong?

(2) What are the perceptions of teachers and students in Hong Kong's Chinese-medium secondary schools towards the use of L1 in English reading lessons?

\section{METHOD}

\section{Research Design}

This study employed a mixed method research approach, which included the collection of quantitative and qualitative data. With the use of survey forms as quantitative data, it was expected to observe specific patterns of the use of L1 teaching and learning strategies among the participants of different schools. Classroom observations and interviews, as qualitative data, aimed at exploring the perception and reasons behind of teacher and student participants using the L1 teaching and learning strategies, as well as the effects that brought by them. By integrating both methods, the perceptions and reasons expressed by the participating teachers and students in the interviews could 
assist in explaining and interpreting the daily use of L1 teaching and learning strategies by them in English reading lessons.

\section{Participants}

This research included 3 secondary schools (SCH1-3). They were stratified samples which were selected purposively so that the sampled schools were representable for Hong Kong CMI secondary schools. School A (SCH1), B (SCH2) and C (SCH3) located in Shek Kip Mei, Kwun Tong and Tuen Mun respectively with similar demographical characteristics. The schools located in districts with mainly middle and lower-class residents. They are CMI schools under the policy of the government. In other words, they use entirely Cantonese as Medium of Instruction (MOI) for all content subjects except English language lessons. In English lessons, only occasional use of Cantonese is allowed. According the study conducted by the Education Bureau (2006), CMI schools could be categorized into three types with regards to students' ability. They are Chinese-medium-High, Chinese-medium-Medium, and Chinese-medium-Low. Therefore, the sample schools were selected to fit into each grouping in order to have a comprehensive study on CMI schools. Based on the information provided by the participating schools' websites, school administrators and teaching staff, the academic ability of students in School $\mathrm{C}$ is the highest (with mainly Band 2 students), followed by School A (with some Band 2 students and some Band 3 students) and School B (with mainly Band 3 students). The principals and the English panel heads of the participating schools invited their teachers to participate in this study with two suggested criteria. The teacher needs to be an English teacher teaching a Form 2 class, and he or she should have the experience in using L1 as a teaching strategy. Three male teachers (T1-3) teaching English language took part in this study. Their teaching experience ranged from 1 to $>10$ years. All of them possessed a first degree in English Language and a postgraduate Diploma in Education (PGDE). It was also evident from the observation records that they could speak and use English fluently and comfortably. Three classes of secondary 2 students (S1-46) also participated in this study, with a total of 63 students. They are the average classes of the form and the class size ranged between 13 and 30 students. All participating students used Cantonese as their mother tongue. It was observed and reported by the teachers that all the participating students generally had a moderate to low motivation in the English lessons, with an average of low academic performance in English.

\section{Research Materials}

\section{Classroom observation}

There is a total of three 35-70 minute English reading lessons were observed, one visit was assigned to each school. The study adopted natural observation where the strategies of teachers and students using L1 in the reading lessons were explored under their daily classroom settings. By observing the lessons, the strategies proposed by the theoretical framework could be initially validated and new strategies could also be discovered. These L1 teaching and learning strategies used by the participants were recorded for further interrogation in survey forms and interviews. 


\section{Survey form}

Based on the theoretical framework mentioned in the previous chapter, together with the observation findings of the three participating classes across schools, survey forms are set for selected interviewees in each class to state their frequency of use of L1 teaching and learning strategies in English reading lessons on a daily basis. There were two versions of the survey form: the teacher version was in English and the student version was bilingual as requested by the teachers. Each form had two sections, the first section was about the frequency of use of L1 as a teaching strategy and the second was about the frequency of use of L1 as a learning strategy, which consists of 8 and 6 items respectively and with the frequency scale of "frequently", "sometimes", "rarely" and "never".

\section{Interview}

Six retrospective semi-structured interviews were conducted with the participating teachers and three groups of students (one-third of each class) to answer the two research questions after the completion of the survey forms. The interviews aimed at discovering the ways that L1 use in the classrooms helps teaching and learning and exploring teachers' and students' perceptions towards the use of L1 in English reading lessons.

\section{Research Procedure}

A classroom observation on English reading was first conducted in each school. After the observations, around one-third of the students from each class were randomly selected by the teachers to attend the group interviews; the English teacher from each class was also invited to have an individual interview. Before the interviews, they had to complete a survey form. The lessons observed and interviews conducted in different schools were not undergone on the same day as regards to the limitation of time per day, which allowed the enhancement of the validity and reliability of the data collection process.

\section{FINDINGS}

With regards to the research questions: 1) How does the use of L1 help teaching and learning in English reading lessons of Chinese-medium secondary schools in Hong Kong? 2) What are the perceptions of teachers and students in Hong Kong's Chinesemedium secondary schools towards to use of L1 in English reading lessons? Survey forms and interviews were administered and conducted to examine the questions and the results are presented in the following paragraphs.

How does the use of $\mathrm{L1}$ help teaching and learning in English reading lessons of Chinese-medium secondary schools in Hong Kong?

By summarizing the views from the participants, there were in total 5 positive effects that L1 teaching and learning strategies had on the English reading lessons. They believed that the L1 strategies could save class time, ensure students' understanding, encourage their participation, ensure their improvement and increase their word power. 


\section{Save class time}

All of the participating teachers mentioned that L1 bottom-up language focused teaching strategies were helpful in saving class time. They claimed that it was more convenient and efficient to translate target vocabulary for students directly in Cantonese so as to "use classroom time effectively" (T1). They explained that if there were Chinese equivalents for some abstract or ambiguous nouns and phrases, they did not have to spend more than 5 minutes to explain with some real cases or examples to make the illustrations (T2, T3), as a result they could cover more in one period. Students also agreed that with instant Cantonese translation, they did not have to "struggle with the meaning of words even with abundant explanation in L2" (S38) and "affected the progress of the lessons" (S44). Besides, as reading lessons tended to have a larger amount of new language input, students might have more queries in reading lessons. Teachers expressed that L1 condition-oriented learning strategies could increase the overall efficiency of the lessons. Students also agreed that with Cantonese, they could get answers quickly and proceed to other parts of the materials (S16, S31, S34).

\section{Ensure students' understanding}

Teacher respondents reported that since some of the learning materials were authentic, students might find difficulties in getting the word meaning in L2 as they were "out of their understanding" (T2), therefore L1 bottom-up language focused teaching strategies were useful to ensure their understanding. They further emphasized that they had to make sure that a majority of the class understood the target points but "not just one or two of them" (T1). Students echoed such views by expressing that even teachers had used simple L2 words to explain the reading materials, they might not be able to grasp them (S6, S14, S36). Meanwhile, most of them reflected that Cantonese translations or explanations are more memorable (S34, S36, S44). Although teachers reflected that they were not incline to use L1 top-down teaching strategies, student participants reflected that with additional materials provided by the teachers (visual aids with L1 captions and subtitles), they could understand what the materials were trying to convey directly (S7, S38, S46).

\section{Encourage students' participation}

All teacher respondents agreed that by using L1 bottom-up language focused teaching strategies, students were provided with L1 translations and explanations, which could enable them to understand more in a fast manner. They were thus inspired to participate more in classroom discussion as "they would have a lot of ideas in their minds" (T2). Students also elaborated that they tended to chit-chat with their neighbours and daydreaming in class if they failed to get the English translations and explanations consecutively (S38. S44); if they had a better understanding of the passage right at the beginning with the help of L1 translations and explanations, they could develop genuine interest of the topic and willing to "listen more than usual" (S7, S14). Student participants also mentioned that with L1 top-down language focused teaching strategies, they might find reading lessons less "stressful" (S35) and more "interesting" (S35, S38). With teachers' sharing, students were more willing to participate actively as the 
teachers' L1 daily experience resonate with the students (S42, S44). With regards to the L1 condition-oriented learning strategies, the participating teachers observed that students tend to participate more in the lessons if they used Cantonese to express their ideas, as they were "afraid of making grammar mistakes" (T1) and "feel embarrassed" (T2, T3). Students also showed similar responses, they mentioned that it was "peculiar" for them to use English entirely to share personal experience or ideas with their peers, as "no one would do so" (S36). Instead, using L1 was more "cordial" (S42) and that they were more eager and opened to voice their opinions in class.

\section{Ensure students' improvement on L2 learning items}

It was also found that L1 condition-oriented teaching strategies could enhance the knowledge level of students as mentioned by the teacher respondents. Therefore, if "good" questions were raised in the lessons (T2), teachers tended to use L1 to make clarifications; if students faced any difficulties, teachers also chose to make comments in L1. By doing so, teachers could ensure all students were given a chance to improve on that particular learning item. Students also made a remark that they could not get all the clarifications or comments made by teachers during lessons in L2 (S2, S6, S34, S31).

Increase students' word power in English language

The participating teachers further reflected in the interviews that students had very limited word power and that they had "no words in their minds" in L2 (T2). Therefore, they might hesitate in discussion and failed to come up with ideas for the reading materials (T3). Students also expressed their difficulties in using L2 that sometimes that naturally switched to express in Cantonese when they were not confident in the accuracy of their choice of words in English (S14). With the help of L1 condition-oriented learning strategies, students added that there were a lot more variety (e.g. synonyms) in Cantonese, which helped them to express themselves better (S7, S44, S46).

What are the perceptions of teachers and students in Hong Kong's Chinesemedium secondary schools towards to use of $\mathrm{L} 1$ in English reading lessons?

In the following subsections, the frequency of using L1 teaching and learning strategies were shown to illustrate the actual use of L1 in CMI secondary schools' English reading lessons according to the point of views from teacher and student participants. It was found that there was a different degree of discrepancy between the point of views from teachers and students 1) towards the use of L1 teaching strategies, 2) the use of L1 teaching strategies across schools with different bandings, and 3) the use of L1 learning strategies. 
Table 1

Frequency of Use of L1 Teaching Strategies (Teachers' and Students' Point of Views [POV])

\begin{tabular}{|c|c|c|}
\hline Frequency of use & L1 teaching strategies & Category \\
\hline \multirow{5}{*}{ Frequently } & (Teachers' POV) & \\
\hline & $\begin{array}{l}\text { 2. Make translation of vocabulary, expressions and/ } \\
\text { or concepts. } \\
\text { 3. Give explanation and elaboration of vocabulary, } \\
\text { expressions and/ or concepts. } \\
\text { (Students' POV) }\end{array}$ & $\begin{array}{l}\text { Bottom-up language } \\
\text { focused } \\
\text { Bottom-up language } \\
\text { focused }\end{array}$ \\
\hline & $\begin{array}{l}\text { 2. Make translation of vocabulary, expressions and/ } \\
\text { or concepts. }\end{array}$ & $\begin{array}{l}\text { Bottom-up language } \\
\text { focused }\end{array}$ \\
\hline & $\begin{array}{l}\text { 3. Give explanation and elaboration of vocabulary, } \\
\text { expressions and/ or concepts. }\end{array}$ & $\begin{array}{l}\text { Bottom-up language } \\
\text { focused }\end{array}$ \\
\hline & $\begin{array}{l}\text { 1. Say something related to his/ her shared culture } \\
\text { and/ or everyday life. }\end{array}$ & $\begin{array}{l}\text { Top-down language } \\
\text { focused }\end{array}$ \\
\hline \multirow{8}{*}{ Sometimes } & (Teachers' POV) & \\
\hline & 4. Make clarification. & Condition-oriented \\
\hline & $\begin{array}{l}\text { 7. Give instructions and/ or reminders about the } \\
\text { reading lessons. }\end{array}$ & Condition-oriented \\
\hline & $\begin{array}{l}\text { 1. Say something related to his/ her shared culture } \\
\text { and/ or everyday life. }\end{array}$ & $\begin{array}{l}\text { Top-down language } \\
\text { focused }\end{array}$ \\
\hline & $\begin{array}{l}\text { 6. Talk to students personally in class } \\
\text { (Students' POV) }\end{array}$ & Condition-oriented \\
\hline & 4. Make clarification. & Condition-oriented \\
\hline & $\begin{array}{l}\text { 7. Give instructions and/ or reminders about the } \\
\text { reading lessons. }\end{array}$ & Condition-oriented \\
\hline & 6. Talk to students personally in class & Condition-oriented \\
\hline \multirow{6}{*}{ Rarely } & (Teachers' POV) & \\
\hline & 5. Give personal feedback and/ or comments. & Condition-oriented \\
\hline & $\begin{array}{l}\text { 8. Show visual input (with Cantonese words or } \\
\text { subtitles) }\end{array}$ & $\begin{array}{l}\text { Top-down language } \\
\text { focused }\end{array}$ \\
\hline & (Students' POV) & \\
\hline & 5. Give personal feedback and/ or comments. & Condition-oriented \\
\hline & $\begin{array}{l}\text { 8. Show visual input (with Cantonese words or } \\
\text { subtitles) }\end{array}$ & $\begin{array}{l}\text { Top-down language } \\
\text { focused }\end{array}$ \\
\hline
\end{tabular}

Slight discrepancy between teachers' and students' POV of using L1 teaching strategies

Teachers' and students' perceptions towards the frequency of use of the L1 teaching strategies in English reading lessons from the three schools were grouped and ranked (see Table 1). The categories were also displayed according to the three categories discussed in the literature review, namely top-down language focused teaching strategies, bottom-up language focused teaching strategies and condition-oriented teaching strategies. It was observed that there was a match between the perceptions of the two parties towards the strategies apart from Item 1 . Teachers were not aware that they had used the top-down language focused strategy more frequently than they perceived, and they reflected in the interviews that they did not prefer using them in 
lessons; however, students in general expressed that these strategies (including Item 8) were useful for their learning in English reading. Both groups showed that bottom-up language focused teaching strategies were frequently used by teachers in the English reading lessons, followed by condition-oriented teaching strategies and top-down language focused teaching strategies.

Table 2

Discrepancy of the Frequency of Use of L1 Teaching Strategies (Teachers' Point of View)

\begin{tabular}{|c|c|c|c|}
\hline L1 teaching strategies & T1 (SCH1) & $\mathrm{T} 2(\mathrm{SCH} 2)$ & T3 (SCH3) \\
\hline $\begin{array}{l}\text { 1. Say something related to his/ her shared culture and/ or } \\
\text { everyday life. }\end{array}$ & Rarely & Sometimes & Sometimes \\
\hline 2. Make translation of vocabulary, expressions and/ or concepts. & Frequently & Frequently & Frequently \\
\hline $\begin{array}{l}\text { 3. Give explanation and elaboration of vocabulary, expressions } \\
\text { and/ or concepts. }\end{array}$ & Frequently & Frequently & Frequently \\
\hline 4. Make clarification. & Frequently & Sometimes & Sometimes \\
\hline 5. Give personal feedback and/ or comments. & Rarely & Sometimes & Rarely \\
\hline 6. Talk personally with students in class. & Frequently & Rarely & Sometimes \\
\hline 7. Give instructions and/ or reminders about the reading lessons. & Sometimes & Rarely & Sometimes \\
\hline 8. Show visual input (with Cantonese words or subtitles) & Rarely & Never & Rarely \\
\hline
\end{tabular}

Larger discrepancy between teachers' POV of using L1 teaching strategies across schools with different bandings

Table 2 showed the discrepancy of the frequency of use of L1 teaching strategies based on the perception of the teacher in each participating school. It illustrated that all the items except Items 2, 3 and 6 had slight discrepancy, as all the teachers reflected that they used Items 2 and 3 frequently in the lessons; whereas a large discrepancy was found in Item 6, for which each teacher had a different frequency of use towards talking personally with students in class in L1. It also revealed that T1 from SCH1 used more L1 condition-oriented teaching strategies (Items 4 and 6) when compared to teachers from the other two schools with higher bandings.

Table 3

Top 3 L1 Teaching Strategies that Teachers Use Frequently (Students' Point of Views)

\begin{tabular}{|c|c|c|c|}
\hline Ranking & SCH1 & $\mathrm{SCH} 2$ & $\mathrm{SCH} 3$ \\
\hline $1 \mathrm{st}$ & $\begin{array}{l}\text { 4. Use Cantonese to make } \\
\text { clarification. }\end{array}$ & $\begin{array}{l}\text { 1. Use Cantonese to say } \\
\text { something related to his/ her } \\
\text { shared culture and/ or } \\
\text { everyday life. }\end{array}$ & $\begin{array}{l}\text { 2. Use Cantonese to make } \\
\text { translation of vocabulary, } \\
\text { expressions and/ or concepts. }\end{array}$ \\
\hline 2nd & $\begin{array}{l}\text { 2. Use Cantonese to make } \\
\text { translation of vocabulary, } \\
\text { expressions and/ or concepts. } \\
\text { 3. Use Cantonese to give } \\
\text { explanation and elaboration of } \\
\text { vocabulary, expressions and/ or } \\
\text { concepts. }\end{array}$ & $\begin{array}{l}\text { 2. Use Cantonese to make } \\
\text { translation of vocabulary, } \\
\text { expressions and/ or concepts. }\end{array}$ & $\begin{array}{l}\text { 3. Use Cantonese to give } \\
\text { explanation and elaboration } \\
\text { of vocabulary, expressions } \\
\text { and/ or concepts. }\end{array}$ \\
\hline $3 \mathrm{rd}$ & $\begin{array}{l}\text { 7. Use Cantonese to give } \\
\text { instructions and/ or reminders about } \\
\text { the reading lessons. }\end{array}$ & $\begin{array}{l}\text { 3. Use Cantonese to give } \\
\text { explanation and elaboration } \\
\text { of vocabulary, expressions } \\
\text { and/ or concepts. }\end{array}$ & $\begin{array}{l}\text { 7. Use Cantonese to give } \\
\text { instructions and/ or reminders } \\
\text { about the reading lessons. }\end{array}$ \\
\hline
\end{tabular}


Larger discrepancy between students' POV of teacher using L1 teaching strategies across schools with different bandings

The above table showed the top three L1 teaching strategies that teachers used frequently according to the students from each participating school. As mentioned previously, most of the students reflected that teachers always used Items 2 and 3, despite the banding of the schools (please refer to methodology) they were attending. For SCH1 and SCH3, teachers tended to use more Cantonese to give instruction and/ or reminders about the reading lessons (condition-oriented teaching strategy) than $\mathrm{SCH} 2$. Almost all the interviewees from SCH1 mentioned that their teacher used Cantonese to make clarification (condition-oriented teaching strategy) frequently, where most of the students from $\mathrm{SCH} 2$ and $\mathrm{SCH} 3$ reported that teachers only sometimes did so.

Table 4

Frequency of Use of L1 Learning Strategies (Teachers' and Students' Point of Views [POV])

\begin{tabular}{|c|c|c|}
\hline Frequency of use & L1 learning strategies & Category \\
\hline \multirow{9}{*}{ Frequently } & (Teachers'POV) & \\
\hline & $\begin{array}{l}\text { 1. Express in Cantonese when it is difficult to show understanding } \\
\text { (and progressiveness) of the materials. }\end{array}$ & Condition-oriented \\
\hline & $\begin{array}{l}\text { 3. Express difficulties in Cantonese to the teacher in completing a } \\
\text { task. }\end{array}$ & Condition-oriented \\
\hline & $\begin{array}{l}\text { 5. Provide each other with help in Cantonese throughout the } \\
\text { English reading lessons. }\end{array}$ & Condition-oriented \\
\hline & $\begin{array}{l}\text { 6. Speak or write Cantonese translation for the reading materials } \\
\text { without teacher's prompting. }\end{array}$ & Condition-oriente \\
\hline & $\begin{array}{l}\text { 4. Express in Cantonese when there is no appropriate English } \\
\text { words to carry out group work. }\end{array}$ & Condition-oriente \\
\hline & (Students' POV) & \\
\hline & $\begin{array}{l}\text { 5. Provide each other with help in Cantonese throughout the } \\
\text { English reading lessons. }\end{array}$ & Condition-orient \\
\hline & $\begin{array}{l}\text { 6. Speak or write Cantonese translation for the reading materials } \\
\text { without teacher's prompting. }\end{array}$ & Condition-oriente \\
\hline \multirow{4}{*}{ Sometimes } & (Teachers'POV) & \\
\hline & $\begin{array}{l}\text { 2. Express in Cantonese when asking the teacher for clarification. } \\
\text { (Students' POV) }\end{array}$ & Condition-oriented \\
\hline & $\begin{array}{l}\text { 4. Express in Cantonese when there is no appropriate English } \\
\text { words to carry out group work. }\end{array}$ & Condition-oriente \\
\hline & $\begin{array}{l}\text { 1. Express in Cantonese when it is difficult to show understanding } \\
\text { (and progressiveness) of the materials. }\end{array}$ & Condition-oriente \\
\hline \multirow{3}{*}{ Rarely } & (Students' POV) & \\
\hline & $\begin{array}{l}\text { 3. Express difficulties in Cantonese to the teacher in completing a } \\
\text { task. }\end{array}$ & Condition-orient \\
\hline & 2. Express in Cantonese when asking the teacher for clarification. & Condition-or \\
\hline
\end{tabular}

Large discrepancy between teachers' and students' POV of using L1 learning strategies

In Table 4, teachers' and students' perceptions towards the frequency of use of the L1 teaching strategies in English reading lessons from the three schools were grouped and ranked. It was observed that there was a greater discrepancy between the perceptions of the two parties towards the learning strategies. Both groups maintained that students 
provided each other with help in Cantonese and spoke or wrote Cantonese translation for the reading materials without teacher's prompting in the lessons frequently. However, discrepancy was observed for Items 1, 2, 3 and 4, in which Item 3 had the largest difference. Students mentioned that they rarely expressed difficulties in Cantonese to the teacher in completing a task but teachers observed that they frequently did so in the reading lessons.

\section{DISCUSSION}

The purpose of this study was to explore the pedagogical and affective impacts of using L1 in English reading lessons. Although positive effects were found in using L1 in English reading lessons, the effectiveness of each categories of L1 teaching and learning strategies varied with the consideration of frequency and perceptions of participants using these strategies. In the section, the difference found among the categories of L1 teaching and learning strategies will be discussed, before turning the attention to research limitation and future directions for research.

The importance of using L1 bottom-up language focused teaching strategies for students' understanding of reading materials

Students should be a "code breaker" and "text participant" in an English reading lesson in order to become a successful reader (Freebody and Luke, 1990, p. 7). Therefore, the gaining of meanings through decoding and the construction of meanings through the information in the texts and students' existing knowledge become students' essential first two steps to understand the reading materials in the lessons. Yet, the findings showed that most of the student participants with low English proficiency got stuck with these two steps. They have difficulties in decoding (e.g. 'I don't know how to even pronounce the word' [S7]) and constructing meanings for the texts (e.g. '...even if I had linked up the upper and lower part of the passage, I failed to get the meaning' [S36]) due to their weak foundation in English. The situation "does not improve much" even with extra help from the teachers using L2 (S6, S14, S16, S35, S44). Both participating parties reflected that it was difficult to ask students to participate in the reading lessons if they didn't even know the meanings of the words (T1, T2, T3), as they had a sense of "incompetence" and "helplessness" (S5, S6, S34, S46). However, both groups claimed that L1 bottom-up language focused teaching strategies played an important role in this situation and it was reported in the finding that this category of strategies were being frequently used in the reading lessons. It was found that having the ability to decode and construct meanings in reading were crucial and the above participants' perceptions reflected that the use of L1 bottom-up language focused strategies enabled students to participate in these two steps and thus having a better understanding of the reading materials. Moreover, most of the participants mentioned that the L1 bottom-up language focused strategies increased their motivation to participate more in the lessons and "continue to discover the texts" (S6, S7).

The use of $\mathrm{L} 1$ condition-oriented learning strategies for students' improvement on English reading

The construction of meanings in the texts could further be done by discussing their own interpretations in pairs, groups or class discussions by linking their existing knowledge 
to their understanding of the texts. Yet, the findings showed that they did not have enough word power to formulate all their ideas. Together with the affective factors like peer influence, they were still reluctant to participate in the discussion of the texts. Therefore, L1 condition-oriented learning strategies reduced their affective barriers by providing them with a more secured environment to construct their ideas. They also enabled students to construct their ideas more comprehensively and accurately. According to T1, T2 and T3, most of the students sometimes used L1 to complete meanings during their discussions, they might use one to two Cantonese keywords or phrases in the discussion which enabled them to arrive to the meaning that they were intended to construct. Such affective factors brought by L1 also motivated students to ask their classmates and teachers more questions, as well as spoke and wrote more for their reading materials in order to achieve the construction of meanings. It was a significant move because seldom did students in general participate actively in the reading lessons, as it was "highly dominated by teachers" (T1), let alone the students with lower English proficiency. The motivation to ask questions enabled teachers to check on students' concepts, as well as to make clarification if necessary.

With the employment of L1 condition-oriented learning strategies, the word power and the level of participation among the lower ability students in discussion for meaning construction could be increased. They were being empowered in the lessons to interpret the meanings and exchange ideas with their peers. Progressiveness might thus occur when the word power and motivation of the students increased gradually over time. Yet, it was worth-noting that such progressiveness might not happen if students had not decoded the words and constructed the meanings in the texts, therefore most of the use of L1 condition-oriented learning strategies was considered by the participating teachers and students after using L1 bottom-up to achieve their basic teaching and learning objectives.

Teachers' and students' views on the use of L1 top-down language focused teaching strategies

Although it was mentioned in the findings that students in general expressed that the usefulness of L1 top-down language focused teaching strategies for their learning in English reading lessons, teachers were not aware that they had used the strategies more frequently than they perceived as they reflected that they did not prefer using them in lessons. Most of the teacher participants pointed out that students in general were interested to what teacher's sharing of daily life experiences. Unless there were words that had been "localized" or "domesticized" (T3), teachers believed that they could still share in L2. Indeed, most of the students mentioned that they "enjoyed a lot" (S34, S36, S42, S46) and were "energized" (S16, S31, S34, S35) when teachers shared their own stories and experiences despite the choice of using L1 or L2. They also added that they could mostly get what the teachers said even if they used L2 (S38, S42, S44, S45). Similarly, most of the teacher participants tended not to show L1 subtitles or photo captions for visual inputs like videos and pictures unless students were lost in the visual inputs (T1, T2, T3). Most of the students on the one hand, as reflected by the teacher participants, were able to understand most of the content of the videos and pictures 
based on what they had learnt from the texts as well as from the context, on the other hand, they were initially "motivated" by the visual inputs and willing to pay more attention to them (S27, S44, S46). It showed that the initial understanding of the text itself was the most important and since most of the students were motivated by visual inputs, the use of L1 seemed not to be that significant in this category unless the words that they failed to get from the inputs might affect their understanding.

\section{The use of L1 depends largely on students' English proficiency and teaching contexts}

All teacher respondents mentioned in the interviews that they tried hard to "use English as much as possible" (T1) because essentially they were teaching English. However, students indeed "understand better, understand quicker and participate more" if both parties used Cantonese on some occasions (T1). They also pointed out that such situation (i.e. whether to use L2 entirely or to incorporate L1) depended largely on students' abilities and class time. According to the teacher from $\mathrm{SCH} 2$, he claimed that "if the class time is sufficient, if the teaching schedule is not tight, if the students' abilities are high enough, teachers can use English to conduct the lesson completely, because everything allows them to do that". However, students not only had difficulties in understanding authentic materials, but also the glossary in the textbooks (T2, T3). Teacher participants expressed that they did not have sufficient class time to explain everything in detail, and it was also not guaranteed that all students understood the English explanations or clarifications (T1, T3). Therefore, the use of L1 helped as students could be "more focused in the lesson", and the lessons "will have students" participation" (T2). Student participants agreed such claim and added that it was "inevitable" (S7, S14, S31, S35, S38, S44) to use L1 in their English reading lessons. They mentioned that having English reading lessons with content entirely in L2 is demanding (S35, S38, S44, 46). With the use of L1 strategies, they could at least be attracted by the lesson atmosphere as well as be encouraged to get involved in the lessons. Many participating students also reflected that they were aware of the issue of time constraint, and further claimed that the use of L1 speeded up the overall progress of the lessons, no matter for teachers' teaching or their discussion.

As reported in the findings, all teachers tended to use L1 bottom-up language focused strategies frequently, followed by the condition-oriented and top-down strategies. However, it was observed and recorded that SCH1, with a lower banding among the three schools, used more condition-oriented strategies such as making clarifications, talking to participating students personally in class and giving instructions/ reminders of reading lessons in L1 with less top-down language focused strategies (see Tables 2 and 3 ). According to the classroom observation, T1 from SCH1 spent most of the time in teaching vocabulary throughout the lesson, yet not all the student participants were paying attention and the teacher spent the remaining time of each sub section to talk to the students individually in L1 to reinforce the lesson content. The proportion of using $\mathrm{L} 1$ in affective aspects was higher than that in $\mathrm{SCH} 2$ and $\mathrm{SCH} 3$. Moreover, more student respondents from SCH1 also showed a higher dependency in using L1 as a learning strategy in the reading lessons. The responses and corresponding attitudes of 
participating students in $\mathrm{SCH} 2$ and $\mathrm{SCH} 3$ were slightly more positive and dependent towards the use of L1 in English reading lessons. It seemed that there was a negative relationship between the level of English proficiency of students and the amount of L1 used in English reading lessons, and that the use of L1 worked best for the instructional (bottom-up language focused) and affective aspects (condition-oriented) of the English reading lessons which were attended by students with lower English proficiency.

\section{Research implications and limitations}

This study revealed that the use of L1 bottom-up language focused teaching strategies was found to be the most essential for teaching and learning in English reading lessons, and the use of L1 condition-oriented learning and teaching strategies were also necessary. Although teachers would like to use L2 as much as possible in the lessons, they were restrained by the English proficiency of students. It implied that the use of L1 in the bottom-up language focused and condition-oriented categories should be reserved and strengthened, so that there is an effective use of L1 in the English reading lessons; in contrast, the use of L1 top-down strategies should be reduced and increase the exposure of English in this category, so that students could be exposed to more L2 in the area that they felt comfortable with. The study also suggested a systematic use of L1 teaching and learning strategies in order to enhance teaching and learning of English in every classroom, therefore future studies should move further to explore and investigate the use of L1 in lessons with other language skills and identify the techniques of using L1 strategies in the English classroom, so that the effect of L1 use could be maximized in English lessons as a whole.

Besides, further examination of the same topic is also needed as several limitations are identified in the study. One limitation of the study is the sample size and the characteristics of the participants. The sample only included 3 classes from $3 \mathrm{CMI}$ schools that are of the same year level. Although the study has targeted 3 schools of different bandings, the findings of the study cannot be generalized to the use of L1 in English reading lessons for ESL learners and their teachers as well as their perceptions to all CMI schools in Hong Kong. It is therefore important for future studies to put a focus on the teachers and students of different backgrounds, so as to sort out the general help of L1 in English reading classrooms by inducing more data for analysis and discussion. Another limitation is the utilization of classroom observations. Since there was a limited amount of classroom observations in this study, the pattern of L1 use by different teachers could not be fully discovered as each reading lesson has its own lesson objective and focus. Therefore, future studies are suggested to include more observations so that more scenarios of the use of L1 could be discovered.

\section{CONCLUSION}

This study investigated the use of L1 in English reading lessons and the perceptions of teachers and students towards it in Hong Kong Chinese-medium secondary schools. While it was found that there was a negative relationship between students' English proficiency and the use of L1 in English reading lessons and that teachers wanted to use as much L 2 as possible in the lessons, the study stressed on a point that effective L1 use 
was essential for students' learning as it had positive impacts on teaching and learning in terms of supporting students with low English proficiency to gain and construct meaning from reading materials, as well as encouraging their participation and progression. In other words, the use of L1 bottom-up language focused teaching strategies and L1 condition-oriented teaching and learning strategies should be remained, whereas the use of L1 top-down language focused teaching strategies should be reduced, so that L1 could be used strategically and effectively in English reading lessons. Moreover, in order to emphasize and promote the effective use of L1, there is a need for further research to extend the study to other language skills. By knowing how L1 should be employed more strategically, students' learning could be assisted and enhanced. After all, no matter what how much L1 is used in a lesson, it must safeguard the best interests of each individual student.

\section{REFERENCES}

Antón, M., \& DiCamilla, F. (1998). Socio-cognitive functions of L1 collaborative interaction in the L2 classroom. Canadian Modern Language Review, 54(3), 314-353.

Atkinson, D. (1993). Teaching monolingual classes: Using L1 in the classroom. Harlow: Longman Group Ltd.

Auerbach, E. (1993). Re-examining English only in the ESL classroom. TESOL Quarterly, 27(1), 18-20.

Bialystok, E. (2001). Bilingualism in development: Language, literacy and cognition (pp.174-175). Cambridge: Cambridge University Press.

Carson, E., \& Kashihara, H. (2012). Using the L1 in the L2 classroom: The students speak. The Language Teacher, 36(4), 41-48.

Castilla, M. A. (2015). Students' reluctance to use English in classroom discussions. Retrieved from https://www.academia.edu/6886289/Students_Reluctance_to_Speak_English_in_Classr oom_Discussions/.

Claus, F., \& Gabriele, K. (1980). Processes and strategies in foreign language learning and communication. Interlanguage Studies Bulletin Utrecht 5(1), 47-118.

Cook, V. (2001). Using the first language in the classroom. The Canadian Modern Language Review, 57, 402-423.

Cortazzi M., \& Jin L. X. (1996). Cultures of learning: Language classrooms in China. In H. Coleman (Ed.), Society and the language classroom (pp. 169-206). Cambridge: Cambridge University Press.

Crawford, J. (2004). Language choices in the foreign language classroom: Target language or the learners' first language? RELC Journal, 35(5), 5-20.

Curriculum Development Council. (2002). English language education: Key learning area curriculum guide (primary 1 - secondary 3). Retrieved from 
http://www.edb.gov.hk/attachment/en/curriculum-development/kla/engedu/cdc_ele_kla_curriculum_guide_(p1-s3)_2002_2801.pdf/

von Dietze, A., \& von Dietze, H. (2007). Approaches to using L1 in the EFL classroom. The Language Teacher, 31(8), 7-10.

Hamouda, A. (2012). An exploration of causes of Saudi students' reluctance. International Journal of English Language Education, 1, 17-34.

Harbord, J. (1992). The use of the mother tongue in the classroom. ELT Journal, 46(4), 350-355.

Hidayati, I. N. (2012). Evaluating the role of L1 in teaching receptive skills and grammar in EFL classes. Indonesian Journal of Applied Linguistics, 1(2), 16-32.

Jackson J. (2002). Reticence in second language case discussions: Anxiety and aspirations. System, 30(1), 65-84.

Lantolf, J. P. (2001). Sociocultural theory and SLA. In R. B. Kaplan (Ed.), Handbook of applied linguistics (pp.109-119). Oxford, Oxford University Press.

Lewis, M. (1993). The lexical approach. London: Language Teaching Publications.

Li, D. C. S. (2017). Multilingual Hong Kong: Languages, literacies and identities. Switzerland: Springer International Publishing.

Liu, M. (2005). Reticence in oral English language classrooms: A case study in China. TESL Reporter, 38(1), 1-16.

Lo, Y. Y. (2015). How much L1 is too much? Teachers' language use in response to students' abilities and classroom interaction in Content and Language Integrated Learning. International Journal of Bilingual Education and Bilingualism, 18(3), 270288.

McCroskey, J. C. (1992). Reliability and validity of the willingness to communicate scale. Communication on Quarterly, 40(1), 16-25.

Meyer, H. (2008). The pedagogical implications of L1 use in the L2 classroom. Maebashi Kyoai Gakuen College Journal, 8, 147-160.

Mikulecky, B. S. (2008). Teaching reading in a second language. London: Pearson.

Polio, C., \& Duff, P. (1994). Teachers' language use in university foreign language classrooms: A qualitative analysis of English and target language alternation. The Modern Language Journal, 78, 313-326.

Shum, T. P. (2008). Students' perceptions of instructional language practices in the English classroom: A case study of a secondary one class in Hong Kong (Unpublished master thesis). University of Hong Kong, Hong Kong.

Tang, J. (2002). Using L1 in the English classroom. English Teaching Forum, 40(1), 36-43.

Wandika, F. A. (2014). Students' reluctance to speak in English classroom interaction at senior high school: A study at SMA Pertiwi 2 Padang. Pendidikan Bahasa Inggris, 4(2), $1-4$. 